\title{
VV.AA: Jurisdicción constitucional y democracia. Actas de las XVI Jornadas de la Asociación de Letrados del Tribunal Constitucional, Tribunal Consti- tucional-Centro de Estudios Políticos y Constitucionales, Madrid, 2011, 391 pp.
}

Desde la aceptación del carácter vinculante de la Constitución se debate en torno a la conveniencia y necesidad de contar con un sistema de justicia constitucional que garantice que el Parlamento no se aparta de la voluntad constituyente. La discusión se articula en torno a una cuestión fundamental: la legitimidad de la justicia constitucional, al producirse el control del representante de los ciudadanos por un órgano que carece de legitimidad democrática directa.

En los últimos años, este debate ha recuperado entre nosotros toda su actualidad. El Tribunal Constitucional (en adelante, TC), sometido a una profunda presión política y mediática, ha visto como la tensión producida en la arena política se trasladaba a su sede para ser resuelta. La polémica suscitada en torno al Estatuto de Autonomía para Cataluña, así como los desencuentros en materia de aborto o de matrimonio entre personas del mismo sexo han terminado residenciándose ante el órgano de justicia constitucional. A ello cabe añadir los problemas para su renovación, que han provocado que desde distintos foros se discutiera su legitimidad, dificultando enormemente el correcto desempeño de su función.

Con este telón de fondo, el análisis riguroso de la cuestión, más que conveniente resulta imprescindible. La obra objeto de reseña constituye una magnífica oportunidad para reflexionar sobre los problemas que desde el punto de vista del principio democrático cabe oponer a la justicia constitucional.

El libro se divide en dos partes. La primera está compuesta por cuatro estudios dedicados al análisis de la inevitable tensión entre la justicia constitucional y la democracia. Estudios que abordan la misma problemática desde ángulos diversos y a su vez, complementarios. Abre la obra un trabajo magistral de Víctor Ferreres Comella, titulado "El Tribunal Constitucional ante la objeción democrática: tres problemas". En él se analizan algunos argumentos que oponer a la objeción contramayoritaria, centrándose el autor en tres temas estrechamente ligados a ella: las posibles vías para asegurar un control democrático sobre el TC; el control sobre las normas ratificadas en referéndum y los límites a las sentencias manipulativas.

El profesor Ferreres analiza el control democrático sobre el TC desde tres puntos de vista: a través del poder de reforma, del legislador ordinario y del nombramiento de sus magistrados. De esta manera, se nos avanza cómo el coste democrático que inevitablemente supone optar por un sistema de control de constitucionalidad de la ley se puede ver en cierta medida compensado por algún grado de control democrático sobre el máximo intérprete de la Constitución. 
Este control se efectúa, para empezar, porque el TC desempeña su función siempre y cuando la Constitución así lo establezca. Nada impide que se someta a reforma para modificar su posición si se considera que la objeción democrática hace insoportable su funcionamiento. Asimismo, también el legislador democrático puede obligar al Tribunal a repensar su doctrina si persiste en interpretaciones que se han considerado contrarias a la Constitución. La aprobación de una norma contraria a la doctrina del juez constitucional obliga a volver a debatir sobre la misma, abriendo un diálogo que puede llevar al TC a ofrecer una interpretación alternativa. Por último, no cabe duda de que un sistema de control democrático sobre el nombramiento de los magistrados del TC permitiría paliar en alguna medida el déficit democrático de la institución. La relevancia de esta cuestión se hace patente en sistemas como el nuestro, en el que el nombramiento de los magistrados se ha convertido en motivo de lucha política, retrasándose en ocasiones la renovación durante años. La opción por un mandato indefinido, previa reforma constitucional, podría, según el autor, paliar algunos de los problemas que a este respecto se presentan.

La cuestión relativa a la relevancia de la participación directa de los ciudadanos en referéndum en la articulación del control de constitucionalidad resulta del máximo interés, habida cuenta del debate suscitado con motivo del pronunciamiento sobre el Estatuto de Autonomía de Cataluña. Tras afirmar que este dato no puede excepcionar lo que establece la LOTC de manera palmaria, esto es, el control de constitucionalidad de los Estatutos, el autor analiza si la ratificación popular debería traducirse en un mayor grado de deferencia hacia la norma, acentuando la presunción de constitucionalidad. Para ello, habría que distinguir aquellos casos en los que la norma objeto de examen resulta competente para regular la materia correspondiente, en cuyo caso, la participación popular podría suponer un reforzamiento de la presunción de constitucionalidad de la ley, de los casos en que la norma se extralimita, regulando materias para las que no es competente. En este caso, la participación popular no debería traducirse en una mayor deferencia hacia el legislador.

Por último, se ofrecen unas interesantes observaciones acerca de las sentencias manipulativas y de los límites a las que las mismas se deben someter para resultar soportables desde el punto de vista democrático. También este caso resulta de especial actualidad debido a la sentencia del Estatuto de $\mathrm{Au}-$ tonomía de Cataluña.

De sumo interés resulta el análisis que el profesor Garrorena Morales efectúa en su trabajo "El debate justicia constitucional-democracia en los procesos constituyentes de 1931 y 1978". En el mismo, tras exponer los motivos por los que antes de 1931 no resultaba posible plantearse la existencia de un sistema de justicia constitucional, se estudian los términos del debate en ambos momentos.

El autor nos acerca a las dudas que la justicia constitucional suscitaba en la época y que explican que la garantía no se incluyera en el proyecto inicial de Constitución republicana. Sólo por una serie de avatares, que encontramos 
relatados en el magnífico trabajo del profesor Garrorena, acabó encomendándose el control del legislador democrático al Tribunal de Garantías Constitucionales. A pesar del tiempo transcurrido, los recelos a la garantía constitucional se amparan en motivos que hoy resultan igualmente válidos.

En contraste con lo sucedido en la Segunda República, el constituyente de 1978 tuvo muy clara la opción por la justicia constitucional, incluyéndola en el proyecto de Constitución sin que suscitara mayor debate. También el legislador ordinario optó de manera decidida por esta garantía, ampliando sus competencias al elaborar la Ley Orgánica del Tribunal Constitucional.

Llama la atención como un debate que parecía superado se ha visto reavivado en los últimos años, por los acontecimientos ya mencionados de supervisión del Estatuto de Autonomía para Cataluña y los problemas en la renovación de los magistrados del Tribunal. Por ello, el análisis del profesor Garrorena, a pesar de centrar la cuestión en los momentos constituyentes referidos, resulta de enorme interés para afrontar los problemas del garante constitucional hoy.

Otro enfoque del problema nos ofrece la interesante aportación del profesor Hierro Sánchez-Pescador, "Derechos, democracia y justicia constitucional", que aborda el estudio de la tensión entre la jurisdicción constitucional y la democracia desde la perspectiva de los derechos.

Para defender el modelo de democracia constitucional desde este punto de vista, relata el autor, se exponen tres argumentos: a) que las restricciones que entraña un modelo de justicia constitucional son necesarias para garantizar los derechos de todos; b) que son necesarias para garantizar los derechos de algunos; c) que son necesarias para garantizar algunos derechos. Se trataría, como nos explica el autor, de proteger los derechos de todos, los derechos de algunos o algunos derechos frente a eventuales decisiones de la mayoría. Se añade además un cuarto argumento: la rigidez de la Constitución y el control de constitucionalidad son condición y consecuencia necesaria del carácter normativo de la Constitución, por lo que el reconocimiento de ese carácter normativo implica necesariamente la limitación de la capacidad legislativa de la mayoría parlamentaria.

Frente a estos argumentos, la objeción contramayoritaria ofrece a su vez una réplica desde el punto de vista democrático, formulando lo que se ha dado en llamar el "constitucionalismo débil", que se caracterizaría por un sistema de control judicial de las leyes, algún grado de rigidez constitucional, un principio de auto-restricción judicial que se deriva de la presunción de constitucionalidad de las leyes y la instrumentación de algún mecanismo que, en caso de desacuerdo, haga posible que la última palabra le corresponda a la mayoría democrática.

Para el autor, sería conveniente aprovechar una eventual reforma de la Constitución para modificar el artículo 168 CE e incluir así alguna de esas opciones, aún cuando la mejor opción a día de hoy es recordar que donde la 
Constitución admite cualquier margen de interpretación, "cualquier alternativa racional es constitucional".

Esta primera parte de la obra se cierra con un trabajo del profesor Poiares Maduro, "Passion and Reason in European Integration". Con un título tan sugerente, el autor argumenta cómo la integración europea permite profundizar en la democratización de los distintos Estados que conforman la Unión Europea.

Para el profesor Poiares, el proceso de integración europea es un proceso para la racionalización de las democracias nacionales. El Derecho de la Unión Europea sería así un instrumento para su constitucionalización, influyendo en la razón de la democracia nacional, mejorándola.

El autor se pregunta además por el origen de la tradicional queja de déficit democrático de la Unión Europea y por la crisis que en los últimos años aqueja al constitucionalismo europeo, incrementada considerablemente con la ampliación, que profundiza en la diversidad económica, social y política de la Unión.

No cabe duda de que en el contexto actual, la Unión Europea se enfrenta con importantes desafíos constitucionales, que brindan la oportunidad de redefinir el proyecto europeo para hacerles frente. Según el profesor Poiares el primer desafío surge, por un lado, de la tensión creciente entre el impacto político de la Unión Europea y las expectativas que crea entre los ciudadanos y por otro, de las políticas que realmente puede adoptar en función de sus competencias. El segundo desafío deriva del aumento del carácter mayoritario de la Unión Europea, tanto en lo relativo al sistema mayoritario en la toma de decisiones como en la ampliación de la representación proporcional de su población. En tercer lugar, la tensión entre el constitucionalismo normativo y el protagonismo que las relaciones intergubernamentales adquieren en la toma de decisiones en el seno de la Unión. Se acepta de manera mayoritaria que la UE ha creado un sistema constitucional de derecho pero las relaciones intergubernamentales siguen teniendo un protagonismo fundamental. El cuarto desafío a que se enfrenta la Unión Europea vendría constituido por la definición de sus fronteras. La ampliación es un exponente claro de la filosofía de integración que ha inspirado la Unión pero al mismo tiempo supone una amenaza a ese mismo proceso.

En definitiva, para el profesor Poiares, los actuales retos a los que se enfrenta la UE la colocan en una situación de crisis existencial. Habría que reajustar las políticas o las expectativas que crean y redefinir los objetivos políticos de la Unión, creando así las condiciones adecuadas para garantizar la confianza, tanto a nivel nacional como europeo y para alcanzar una comunicación sustantiva con los ciudadanos. Asimismo, resulta imprescindible promover una idea de comunidad entre los ciudadanos europeos. Solo así, defiende el autor, conseguiremos la dosis necesaria de pasión en la razón de la integración europea. 
La segunda parte de la obra constituye una crónica de jurisprudencia constitucional del período comprendido entre agosto de 2009 y julio de 2010. Contiene cuatro trabajos, centrados tres de ellos en los derechos fundamentales y el último en el control de constitucionalidad de la ley.

El primer trabajo, de Itziar Gómez Fernández, nos expone de manera clarificadora la jurisprudencia constitucional en materia de derechos fundamentales sustantivos. Sabemos así que en el período comprendido en el estudio se han dictado más de una veintena de sentencias que resuelven demandas de amparo en la cuales se invocan el principio de igualdad (art. $14 \mathrm{CE}$ ), el derecho a la inviolabilidad del domicilio (art. 18.2 CE), las libertades de expresión e información (art. $20 \mathrm{CE}$ ), el derecho a participar en los asuntos públicos (art. 23.2 CE), el principio de legalidad sancionadora (art. 25 CE) y el derecho a no sufrir tratos inhumanos o degradantes (art. 15 CE) en conexión con el derecho a la tutela judicial efectiva (art. $24 \mathrm{CE}$ ).

En segundo lugar, Francisco Moya Hurtado de Mendoza nos ofrece una interesante crónica sobre la jurisprudencia relativa al derecho a la tutela judicial efectiva. En total, cuarenta sentencias en las que el Tribunal aplica la doctrina existente. El autor destaca la STC 43/2010, de 26 de julio, sobre el incidente de nulidad de actuaciones y el papel de los tribunales ordinarios como garantes de los derechos fundamentales tras la reforma de la LOTC operada por la LO 6/2007. Asimismo, se recogen pronunciamientos que aluden a la admisibilidad de la demanda de amparo.

La jurisprudencia relativa a las garantías constitucionales del proceso es analizada por Pablo Colomina Cerezo. En un trabajo de gran utilidad se analizan el derecho a juez ordinario predeterminado por la Ley, el derecho a la defensa, a la asistencia letrada, el principio acusatorio, el derecho a un proceso sin dilaciones indebidas, a un proceso con todas las garantáis y a la presunción de inocencia.

En último lugar, Luis Arroyo Jiménez y Eva Nieto Garrido nos relatan muy bien la crónica de las resoluciones del Tribunal Constitucional recaídas en los procesos de control de constitucionalidad de la ley. Dado que en el período objeto de análisis se comprende la STC 31/2010, de 28 de junio, sobre el Estatuto de Autonomía de Cataluña, la referencia minuciosa a la misma ocupa una parte importante de la crónica, abordando su estudio de una manera sistemática y muy clara. Asimismo se incluyen en la crónica referencias al resto de sentencias de Pleno, que analizan preceptos del Código Penal y a las sentencias de Sala. Finalmente, se incluye una referencia a diversos Autos dictados en relación con cuestiones procesales tales como la admisión a trámite o la suspensión de diversos preceptos de la Ley Orgánica 2/2010, de 3 de marzo, de salud sexual y reproductiva y de la interrupción voluntaria del embarazo.

Esperanza Gómez Corona

Universidad de Sevilla 